\title{
Testosterone inhibits matrix metalloproteinase-1 production in human endometrial stromal cells in vitro
}

\author{
Tomonori Ishikawa, Tatsuya Harada, Toshiro Kubota and Takeshi Aso \\ Comprehensive Reproductive Medicine, Graduate School, Tokyo Medical and Dental University, 1-5-45, Yushima, \\ Bunkyo-ku, Tokyo 113-8519, Japan \\ Correspondence should be addressed to T Ishikawa; Email: t.ishikawa.crm@tmd.ac.jp
}

\begin{abstract}
Androgen receptor (AR) is reported to be expressed in human uterine endometrium, but not much information is available on the role of androgens in human endometrium. The purpose of this study is to investigate the role of androgens in the regulation of matrix metalloproteinase (MMP)-1, which is one of the important MMPs for menstruation and embryo implantation in human endometrium. Human endometrial stromal cells (HESCs) were obtained from human endometrium by enzymatic dissociation method. Purified HESCs were incubated with 17 $\beta$-estradiol (E2), testosterone, or E2 + testosterone. Progestins (natural progesterone or medroxyprogesterone acetate) or vehicle (dimethyl sulfoxide) were also added to the media instead of testosterone. Furthermore, hydroxyflutamide (FLU), a specific AR antagonist, was also supplemented to cultured media. The amounts of MMP-1 in cultured media and in HESC lysates were examined by ELISA measurements and western blotting analysis respectively. The expression of ARmRNA in HESCs RNA was analyzed by RT-PCR. Testosterone significantly inhibited MMP-1 in both cultured media and cell lysates in a dosedependent manner. Progestins also inhibited MMP-1. Furthermore, FLU completely recovered the decrease of MMP-1 induced by testosterone. ARmRNA was detected in all HESCs RNA. The present study demonstrated that the secretion and production of MMP-1 in HESCs in vitro were inhibited by testosterone through androgen receptors in a manner similar to that seen for progesterone. These findings indicate that androgen may play an important role in morphological and functional changes of human endometrium.

Reproduction (2007) 133 1233-1239
\end{abstract}

\section{Introduction}

Human uterine endometrium undergoes monthly cyclic morphological and functional changes during the reproductive period. Once pregnancy is established, the endometrium prepares for blastocyst implantation and maintains the pregnancy. On the other hand, if fertilization does not take place, it undergoes shedding and regeneration. These dynamic structural changes in tissue architecture are crucial for normal uterine physiology (Curry \& Osteen 2003). Human uterine endometrium is a typical steroid hormone-responsive organ under the influence of steroid hormones, especially estrogen and progesterone, but little is known about the action of androgens, which are the other type of steroid hormone. The biological actions of androgens are mediated by androgen receptor (AR), a ligand-dependent transcription factor, which belongs to the nuclear receptor superfamily (Roy et al. 2001). Immunohistochemical localization of AR in the human endometrium has been reported (Mertens et al. 2001,
Slayden et al. 2001, Apparao et al. 2002). Positive immunostaining of $A R$ has been described in endometrial stroma and epithelium in normo-ovulatory women and decreases steadily from the early proliferative phase to the mid-secretory phase (Mertens et al. 2001).

Androgens induced prolactin production in human endometrial stromal cells (HESCs) in vitro (Narukawa et al. 1994) and showed an inhibitory effect on the growth and the secretory activity of endometrial epithelial cells in vitro (Tuckerman et al. 2000). In addition, HOXA-10 expression, which is essential for endometrial development and uterine receptivity to implantation, was suppressed by testosterone in vitro (Cermik et al. 2003). In contrast, hydroxyflutamide (FLU), a specific androgen receptor antagonist, delayed the initiation of implantation, fetal development, and parturition in pregnant rats and suppressed decidualization in pseudopregnant rats (Chandrasekhar et al. 1990). These reports suggest that the endometrium 
itself may be the target of androgens, and androgens may play important roles in human endometrium.

In addition, it has also been documented that hyperandrogenism, which is one of the cardinal features in poly cystic ovary syndromes (PCOS; The Rotterdam ESHRE/ ASRM-Sponsored PCOS consensus workshop group 2004), may have an influence on the endometrium. In PCOS patients, although early pregnancy loss is one of the reproductive problems (Van der Spuy \& Dyer 2004), the exact mechanism and causative factor of this problem has yet to be defined. An association between hyperandrogenism and increased incidence of miscarriage in PCOS patients was reported (Tulppala et al. 1993). Okon et al. (1998) postulated that androgens might have a detrimental effect on endometrial function, preventing effective endometrial development both in the proliferative and secretory phase. High levels of serum androgens have also been associated with recurrent miscarriages in women with or without PCOS (Okon et al. 1998, Bussen et al. 1999). On the other hand, Rai et al. (2000) reported that an elevated serum testosterone concentration was not associated with an increased miscarriage rate. The relationship between hyperandrogenism and increased incidence of miscarriage in PCOS patients is under some current controversy (Checa et al. 2005). The influences of androgens and hyperandrogenism on the endometrium need to be fully elucidated because PCOS is a common endocrinopathy in women of reproductive age (Van der Spuy \& Dyer 2004).

Matrix metalloproteinases (MMPs), in part, regulate dynamic structural changes observed in the uterus throughout the menstrual cycle. In fact, MMPs play a pivotal role in embryo implantation ( $\mathrm{Xu}$ et al. 2000) and the initiation of menstruation (Hampton \& Salamonsen 1994, Marbaix et al. 1995). MMPs are grouped according to their domain structure into collagenases, gelatinases, stromelysins, and matrilysin (Sternlicht \& Werb 2001). Collagenases (MMP-1, MMP8 , and MMP-13) are the only mammalian enzymes that can cleave collagen helices to yield characteristic onequarter to three-quarter products at neutral $\mathrm{pH}$ (Marbaix et al. 1996). Denaturation of fibrillar collagens, which are essential components of endometrial extracellular matrix (ECM) (Aplin et al. 1988) by MMP1 , is necessary for further processing towards menstruation by strolelysins (MMP-3) and gelatinases (MMP-2; Lockwood et al. 1998). Therefore, MMP-1 appears to be important for the endometrial tissue degradation and remodeling.

The purpose of the present study is to investigate the role of testosterone and AR in the regulation of MMP1 in HESCs in vitro using ELISA measurements and western blotting analysis. Furthermore, we compared the effect of testosterone and those of progestins (natural progesterone and medroxyprogesterone acetate (MPA)) with the regulation of MMP-1 in HESCs.

\section{Materials and Methods}

\section{HESC collection and isolation}

Human endometrial tissues were collected from women, who underwent hysterectomy for myoma uteri at Tokyo Medical and Dental University Hospital (Tokyo, Japan). All patients gave written informed consent to the study before sample collection and the study protocol was approved by the local ethical committee of Tokyo Medical and Dental University Hospital. The stage of the menstrual cycle was determined based on the dates of the last menstrual period and was histologically confirmed according to the standard criteria (Noyes et al. 1950). HESCs were prepared as described before (Lockwood et al. 1998). Briefly, endometrial tissue was scraped from the uterine wall immediately after hysterectomy, placed in cold Dulbecco's PBS (D-PBS; Takara, Tokyo, Japan), and rapidly transported to the laboratory. The specimen was washed thoroughly and cut into small pieces. These were treated with $2 \mathrm{mg} / \mathrm{ml}$ collagenase (Gibco) and $50 \mu \mathrm{g} / \mathrm{ml}$ DNase (Sigma) in D-PBS and digested at $37^{\circ} \mathrm{C}$ for $1 \mathrm{~h}$. The endometrial cells digested were filtered through $40 \mu \mathrm{m}$ nylon mesh (Becton Dickinson, Bedford, MA, USA) to remove cell debris and epithelial gland fragments. The cells were plated on $10 \mathrm{~cm}$ plastic dishes (Becton Dickinson) and $2 \mathrm{~h}$ later, non-adherent cells and red blood cells were removed.

\section{HESC culture and steroid hormone treatments}

Tissue culture reagents and steroid hormones were purchased from Sigma unless otherwise specified. HESCs were grown to confluence in a $37^{\circ} \mathrm{C}, 95: 5(\%)$ air/ $\mathrm{CO}_{2}$ incubators in cultured medium:phenol red freeD-MEM/F-12 (Invitrogen Corporation) containing 10\% heat-inactivated and charcoal stripped fetal bovine serum (FBS; Wako, Osaka, Japan) and 1\% AntibioticAntimycotic (Invitrogen Corporation). After confluency, HESCs were washed with D-PBS and treated with $0.02 \%$ EDTA and $0.25 \%$ trypsin (Invitrogen Corporation). To confirm the purity of the purified HESCs, immunocytochemical staining for vimentin, cytokeratin, and CD45 was performed using anti-vimentin, cytokeratin, or CD45 MAB (DakoCytomation, Glostrup, Denmark) as described previously (Tuckerman et al. 2000). The trypsinized HESCs were seeded $20 \times 10^{4}$ /well in 24-well plates (Becton Dickinson) in cultured media containing $10 \mathrm{nM} 17 \beta$-estradiol (E2), $100 \mathrm{nM}$ testosterone, or $\mathrm{E} 2+1$ to $1000 \mathrm{nM}$ testosterone. A measure of $100 \mathrm{nM}$ progestins (natural progesterone or MPA) or vehicle (dimethyl sulfoxide) were also added to the media instead of testosterone in order to compare the effects of testosterone with those of progestins. Furthermore, $1 \mu \mathrm{M} \mathrm{FLU}$, a specific AR antagonist, was added to the media. The media were replaced every 4 days. Culture was terminated on day 8 . All the collected media 
were centrifuged to remove cell debris and the supernatants were stored at $-20{ }^{\circ} \mathrm{C}$ until MMP-1 concentration measurement. The wells were washed twice with cold D-PBS and HESCs were taken for protein preparation.

\section{ELISA for MMP-1}

The cultured media were assayed for MMP-1 levels by ELISA (Amersham Biosciences), which detected total MMP-1 (proMMP-1, activeMMP-1, and MMP-1/tissue inhibitor of metalloproteinase complexes), according to the manufacturer's instructions. Briefly, samples and standards were incubated in microtiter wells precoated with anti-MMP-1 antibody. After washing, a polyclonal antibody to MMP-1 was bound to the MMP-1. Any excess was removed, and then the second antibody bound to the wells was detected using donkey anti-rabbit horseradish peroxidase. The amount of peroxidase bound to each well was determined by the addition of tetramethylbenzidine (TMB) substrate. The reaction was stopped by the addition of sulfuric acid (Wako) and the resultant color was read at $450 \mathrm{~nm}$ in a microplate spectrophotometer by Model 450 Microplate Reader (Bio-Rad Laboratories). The concentrations of MMP-1 in samples were determined by interpolation from a standard curve and then normalized to the protein content of the HESCs. Experiments were done in quadruplicate. The sensitivity of this assay was $1.7 \mathrm{ng} / \mathrm{ml}$, and there was no significant cross-reactivity or interference in the assay with MMP-3, MMP-2, and MMP-9 according to the manufacturer's specification (Amersham Biosciences).

\section{Protein assay and western blotting analysis}

HESCs were lysed with lysis buffer $(50 \mathrm{mM}$ Tris- $\mathrm{HCl} \mathrm{pH}$ 7.5, $0.15 \mathrm{M} \mathrm{NaCl}, 1 \%$ Nodidet P-40, 0.1\% deoxycholic acid, $10 \mu \mathrm{M}$ phenyl methylsulphonyl fluoride, $0.5 \mathrm{mU} / \mathrm{ml}$ apoprotinin, $1 \mu \mathrm{M}$ leupeptin, and $1 \mu \mathrm{M}$ pepstatin) to analyze the expression of MMP-1 protein. Protein content of the HESCs was determined by Micro BCA Protein Assay Reagent Kit (Pierce, Rockford, IL, USA) according to manufacturer's instructions. Samples, each containing equivalent amounts of protein, were separated by $10 \%$ SDS-PAGE and transferred onto PVDF membranes (Atto, Tokyo, Japan). After blocking with Block Ace (Dainipponseiyaku, Osaka, Japan) containing 10\% FBS to prevent non-specific binding of the antibodies, the membranes were incubated with anti-MMP-1 polyclonal antibody (Sigma) (1:1000) overnight at room temperature. After washing with buffer, the membranes were sequentially incubated with horseradish peroxidase-conjugated antirabbit IgG antibody (1:5000) (Amersham Biosciences). The bound antibodies were detected by ECL (Amersham Biosciences) in accordance with the recommended procedure. Quantification was performed by computerized optimal densitometric scanning of images (National
Institutes of Health image program), and then normalized using $\beta$-actin protein as internal standard.

\section{RNA extraction and RT-PCR}

Total RNA was isolated from HESCs using RNeasy mini kits (Qiagen) in accordance with the manufacturer's instructions. The quantity of extracted total RNA was determined by spectrophotometry at 260 and $280 \mathrm{~nm}$. CDNA was prepared from $5 \mu \mathrm{g}$ DNase-treated RNA using the SuperScript First-Strand Synthesis System (Invitrogen Corporation), and one-tenth of the mixture was treated with RT and used as a template for PCR. The primer sequences for human AR were designed according to the published CDNA sequences (Lovely et al. 2000). The sense 5'-AGATGGGCTTGACTTTCCCAGAAAG-3' and the antisense 5'-ATGGCTGTCATTCAGTACTCCTGGA-3' primers were used to amplify a $545 \mathrm{bp}$ fragment. The housekeeping gene glyceraldehyde-3phosphate dehydrogenase was also amplified using the following primers: 5'-TGAAGGTCGGAGTCAACGGATTTG-3' and 5'-GCGCCAGTAGAGGCAGGGATGATG-3', yielding a 628 bp product. PCR amplification was carried out using a PCR core kit (Roche). Samples were amplified in a $50 \mu \mathrm{l}$ PCR solution $(10 \mathrm{mM}$ Tris- $\mathrm{HCl}$ $(\mathrm{pH} 8.3), 50 \mathrm{mM} \mathrm{KCl}, 1.5 \mathrm{mM} \mathrm{MgCl} 2,0.2 \mathrm{mM}$ dNTP, and $2.5 \mathrm{IU}$ Taq polymerase) with 30 cycles of the following sequential steps: denaturation at $94{ }^{\circ} \mathrm{C}$ for $1 \mathrm{~min}$, annealing at $55^{\circ} \mathrm{C}$ for $2 \mathrm{~min}$, and extension at $72{ }^{\circ} \mathrm{C}$ for $3 \mathrm{~min}$ in a GeneAmp PCR System 2700 Thermal Cycler (Applied Biosystems, Foster City, CA, USA). The PCR products were subjected to $2.0 \%$ agarose gel (Takara, Tokyo, Japan) electrophoresis and visualized by ethidium bromide staining. The sequences were determined using an automated ABI Prism 310 sequencer (Perkin-Elmer, Boston, MA, USA) and compared with those of AR to confirm their identity. PCR amplification of samples without prior RT was performed as a negative control.

\section{Statistical analysis}

All experiments were repeated at least three times to ensure reproducibility of the results, and the values are shown as the mean \pm s.D. when applicable. For comparison between unpaired groups, one-way ANOVA was used. Differences were considered significant for a $P$ value less than 0.05 .

\section{Results}

\section{Characterization of isolated endometrial stromal cells}

More than $95 \%$ of isolated endometrial stromal cells showed positive immunocytochemical staining for vimentin, whereas less than $5 \%$ of the cells stained positive for cytokeratin and CD45 (data not shown). 
These results showed that our isolated stromal cells were not contaminated with epithelial cells or leukocytes.

\section{Effect of testosterone on MMP-1 secretion}

Amounts of MMP-1 in cultured media were measured by ELISA. The representative results of MMP-1 concentrations in cultured media are shown in Figs 1-4. E2 had no independent effect on the amounts of MMP-1 in cultured media (Fig. 1). Testosterone markedly suppressed the amounts of MMP-1 in a dose-dependent manner, and the concentrations of MMP-1 were significantly decreased $(P<0.05)$ by $100 \mathrm{nM}$ testosterone when compared with control (vehicle) and E2 alone (Fig. 2). On the other hand, amounts of MMP-1 were also significantly reduced $(P<0.05)$ by both $100 \mathrm{nM}$ MPA and natural progesterone (Fig. 3). Furthermore, the suppression of MMP-1 concentration by MPA was significantly greater than by natural progesterone and testosterone $(P<0.05$; Fig. 3$)$. Thus, the secretion of MMP-1 from cultured HESCs was inhibited by testosterone as well as natural progesterone, and MPA was much more effective in MMP-1 inhibition than natural progesterone and testosterone.

\section{Effect of hydroxyflutamide on testosterone-induced decrease in MMP-1 secretion}

To investigate the influence of AR on the testosteroneinduced decrease in MMP-1 secretion in HESCs, we used FLU; a specific AR antagonist, in the present experiment. Whereas $1 \mu \mathrm{M}$ FLU had no independent effect on the amounts of MMP-1 in cultured media, $100 \mathrm{nM}$ testosterone significantly suppressed MMP- 1 concentration, and FLU completely recovered the decrease in MMP-1 induced by testosterone (Fig. 4). FLU had no influence

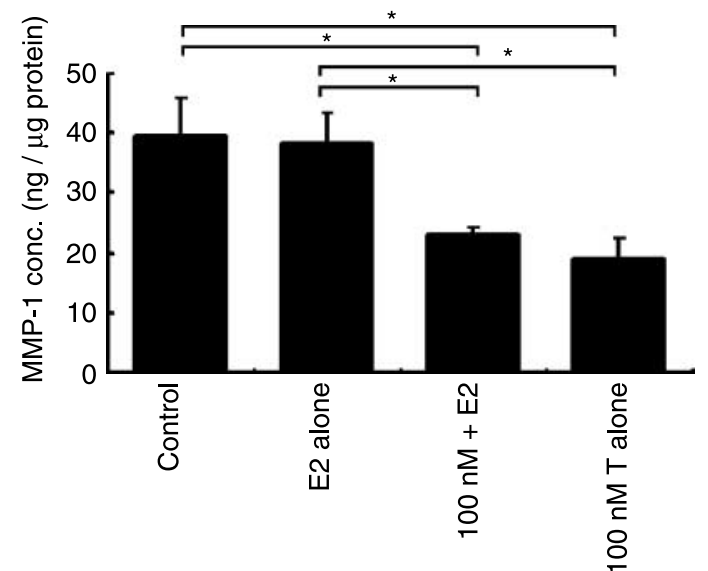

Figure 1 Effect of $17 \beta$-estradiol and testosterone on matrix metalloproteinase-1 (MMP-1) secretion in human endometrial stromal cells (HESCs). The mean concentrations of MMP-1 measured by ELISA in cultured media in which HESCs were treated with $10 \mathrm{nM} 17 \beta$-estradiol (E2) alone, $100 \mathrm{nM}$ testosterone (T), E2 $+\mathrm{T}$, or control (vehicle alone) at 8 days. Bars indicate the mean \pm s.D. of four wells; $* P<0.05$.

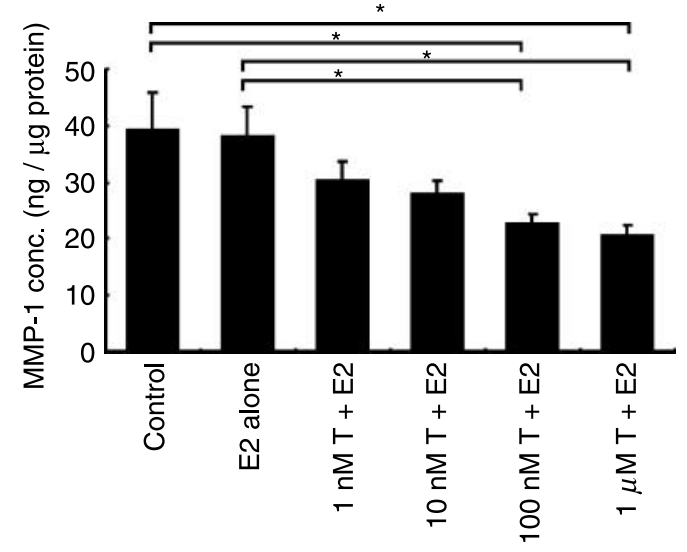

Figure 2 Effect of testosterone on matrix metalloproteinase-1 (MMP-1) secretion in human endometrial stromal cells (HESCs). The mean concentrations of MMP-1 measured by ELISA in cultured media in which HESCs were treated with $10 \mathrm{nM} 17 \beta$-estradiol (E2) alone, $\mathrm{E} 2+$ various concentrations of testosterone $(\mathrm{T})$, or control (vehicle alone) at 8 days. Bars indicate the mean \pm s.D. of four wells; ${ }^{*} P<0.05$.

on the repression induced by natural progesterone but recovered the repression induced by MPA to levels similar to those observed with natural progesterone (Fig. 5). Thus, the testosterone-induced repressive effect on MMP-1 secretion in HESCs was mediated through AR.

\section{Effect of MMP-1 protein levels on HESCs}

To further confirm the effect of testosterone on MMP-1 production in HESCs, we performed quantitative analysis of western blotting. As shown in Fig. 6, testosterone inhibited MMP-1 protein amounts in a dose-dependent manner, and FLU recovered the testosterone-induced repression of MMP-1 production. On the other hand, natural progesterone also suppressed MMP-1 protein expression, and then MPA was more effective in the suppression than testosterone and natural

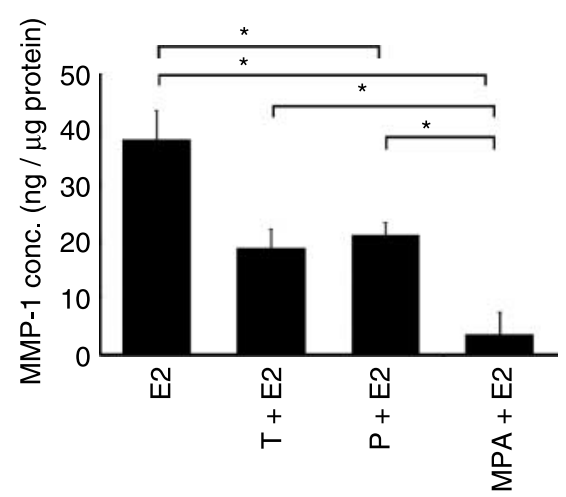

Figure 3 Effect of progestins on MMP-1 secretion in HESCs. The mean concentrations of MMP-1 measured by ELISA in cultured media in which HESCs were treated with $10 \mathrm{nM} 17 \beta$-estradiol (E2) alone or $\mathrm{E} 2+100 \mathrm{nM}$ (natural progesterone $(\mathrm{P})$ or medroxyprogesterone acetate (MPA) or testosterone (T)) at 8 days. Bars indicate mean \pm s.D. of four wells; $* P<0.05$. 


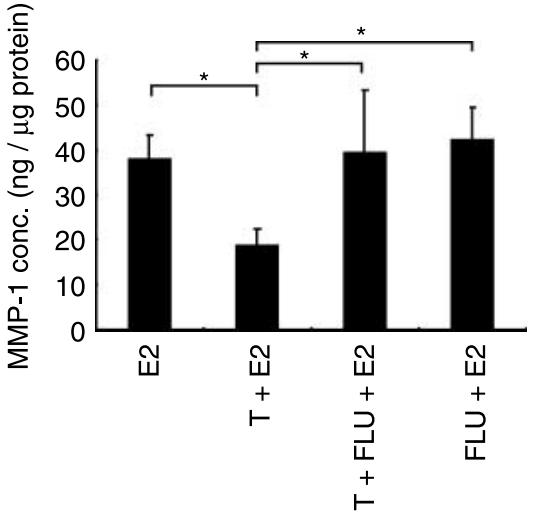

Figure 4 Effect of hydroxyflutamide on the testosterone-induced decrease in MMP-1 secretion in HESCs. The mean concentrations of MMP-1 measured by ELISA in cultured media in which HESCs were treated with $10 \mathrm{nM} 17 \beta$-estradiol (E2) alone, E2 +100 nM testosterone (T) $\pm 1 \mu \mathrm{M}$ hydroxyflutamide (FLU), or E2 + FLU at 8 days. Bars indicate the mean \pm s.D. of four wells; ${ }^{*} P<0.05$.

progesterone (Fig. 7). These results were in agreement with those by ELISA.

\section{Detection of AR mRNA by RT-PCR}

PCR amplification of HESC cDNA with the AR specific primers generated the expected $545 \mathrm{bp}$ fragment from all HESC RNA samples (Fig. 8), and the sequence of products was identical to that of AR. Thus, the expression of AR mRNA was detected in our cultured HESCs.

\section{Discussion}

The present study demonstrated that testosterone inhibited MMP-1 secretion and protein production in

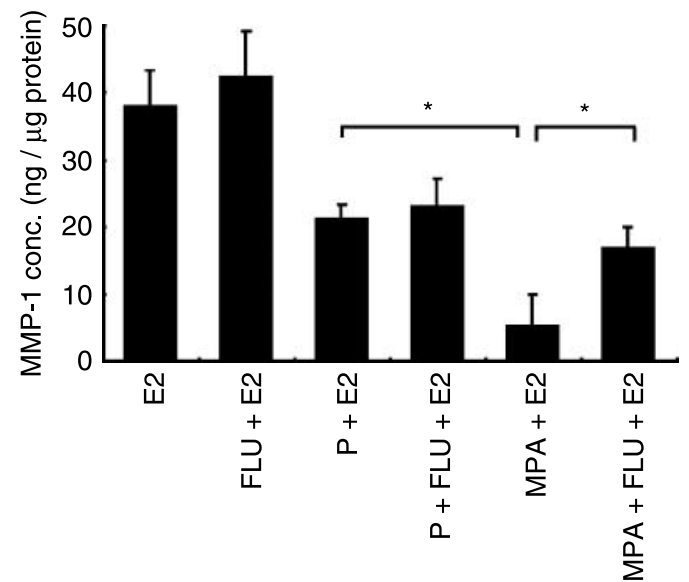

Figure $5 \mathrm{Effect}$ of hydroxyflutamide on the progestin-induced decrease in MMP-1 secretion in HESCs. The mean concentrations of MMP-1 measured by ELISA in cultured media in which HESCs were treated with $10 \mathrm{nM} 17 \beta$-estradiol (E2) alone, E2 $+1 \mu \mathrm{M}$ hydroxyflutamide (FLU), or E2 + $100 \mathrm{nM}$ (natural progesterone (P) or medroxyprogesterone acetate (MPA)) $\pm F L U$ at 8 days. Bars indicate the mean \pm s.D. of four wells; ${ }^{*} P<0.05$.

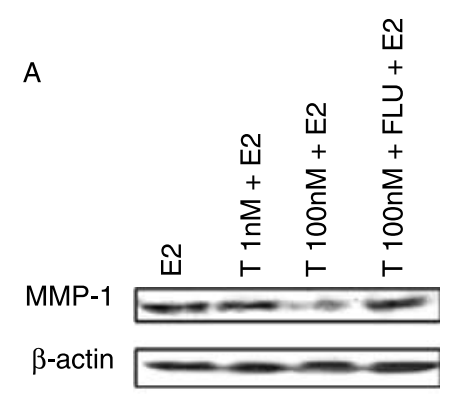

B

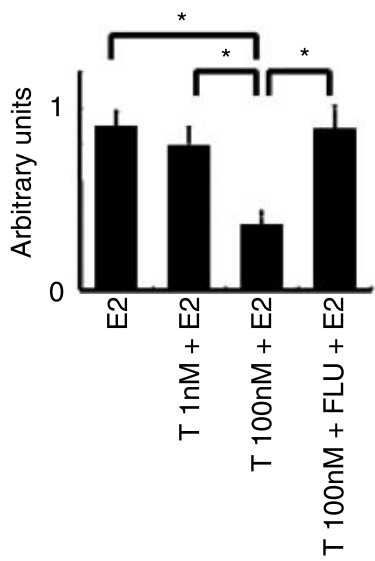

Figure 6 (A) Western blotting analysis of MMP-1 using MMP-1 polyclonal antibody against proteins extracted from HESCs treated with $10 \mathrm{nM} 17 \beta$-estradiol (E2) alone, E2 $+1 \mathrm{nM}$ testosterone (T), or $\mathrm{E} 2+100 \mathrm{nM}$ testosterone ( $\mathrm{T}) \pm 1 \mu \mathrm{M}$ hydroxyflutamide (FLU). Anti MMP-1 antibody reacted with a protein band of $50 \mathrm{kDa}$ (approximate molecular mass of human MMP-1). (B) Densitometric analysis of MMP1 protein in HESCs treated with above mentioned reagents. Bars represent arbitrary units and show the mean \pm s.D. of three independent experiments; ${ }^{*} P<0.05$.

HESCs in vitro (Figs 1, 2, and 6), and that this testosterone-induced inhibition of MMP-1 was completely blocked by FLU (Figs 4 and 6). FLU is a pure non-steroidal anti-androgen without glucocorticoid, progestational, androgenic, estrogenic, or antigonadotropic activity and blocks the androgen receptors in the peripheral target organs without interfering with the circulating levels of hormonal parameters (Ajossa et al. 2002). In the present study, the expression of AR mRNA in cultured HESCs was also determined using RT-PCR. The presence of AR in cultured HESCs, and the observations that testosterone inhibited MMP-1 secretion in vitro and a specific AR antagonist recovered the MMP-1 inhibition induced by testosterone, showed that MMP-1 repression by testosterone was mediated through AR.

The roles of androgens in uterine endometrium are beginning to be investigated. It is suggested that the endometrium itself may be the target of androgens, and androgens may play important roles in human endometrium. The fact that testosterone inhibited MMP-1 production in HESCs in this study is very important, because we clarified one of the mechanisms of 
A

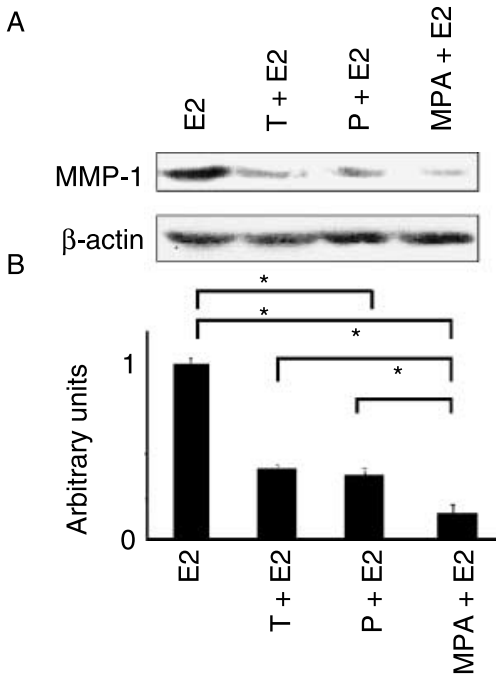

Figure 7 (A) Western blotting analysis of MMP-1 using MMP-1 polyclonal antibody against proteins extracted from HESCs treated with $10 \mathrm{nM} 17 \beta$-estradiol (E2) alone or E2 $+100 \mathrm{nM}$ (natural progesterone $(\mathrm{P})$ or medroxyprogesterone acetate (MPA) or testosterone (T)). Anti MMP-1 antibody reacted with a protein band of $50 \mathrm{kDa}$ (approximate molecular mass of human MMP-1). (B) Densitometric analysis of MMP-1 protein in HESCs treated with above mentioned reagents. Bars represent arbitrary units and show the mean \pm s.D. of three independent experiments; ${ }^{*} P<0.05$.

regulation of MMP-1, which have important roles in implantation and pregnancy.

Expression and secretion of MMPs are tightly controlled by a variety of growth factors, cytokines, oncogenic cellular transformation, tumor promoters, physical stress, and chemical agents such as steroid hormones (Woessner 1991, Nagase \& Woessner 1999). This regulation occurs at the transcriptional or posttranscriptional level, and also at the protein level via their activators, their inhibitors, and their cell surface localization (Sternlicht \& Werb 2001). The precise mechanism of testosterone-induced MMP-1 repression in HESCs was not reported. In the human prostate carcinoma cell line, however, MMP-1 production was inhibited by testosterone and this inhibition occurred not through AP-1 but through a family of Ets-related transcription factors (Schneikert et al. 1996). Dynamic

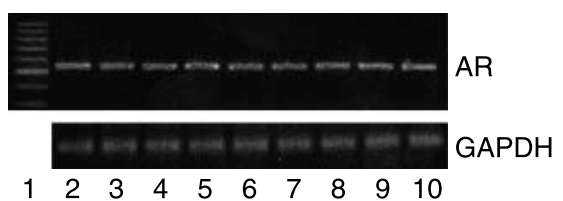

Figure 8 RT-PCR analysis of expression of mRNA for androgen receptor (AR) in HESCs in vitro. AR specific primers generated the expected $545 \mathrm{bp}$ fragment from all samples. GAPDH was used as an internal standard. Lane 1, $100 \mathrm{bp}$ ladder marker; lane 2, $10 \mathrm{nM} 17 \beta$-estradiol (E2); lane 3, E2 + $1 \mathrm{nM}$ testosterone (T); lane 4, E2 + $100 \mathrm{nM} \mathrm{T+1 \mu M}$ hydroxyflutamide (FLU); lane 5, E2 + FLU; lane 6, E2 +100 nM natural progesterone $(\mathrm{P})$; lane $7, \mathrm{E} 2+\mathrm{P}+\mathrm{FLU}$; lane 8, E2 + $100 \mathrm{nM}$ medroxyprogesterone acetate (MPA); lane 9, E2 + MPA + FLU. tissue remodeling occurs as a result of alteration in extracellular matrix in prostate as well as in endometrium (Nagle et al. 1994). Further investigation of the regulatory mechanisms of the repressive effect on MMP-1 production by testosterone in HESCs is needed.

In addition, a decrease in MMP-1 induced by natural progesterone and MPA in HESCs was also demonstrated in the present study (Figs 3 and 7). Furthermore, we demonstrated that MPA was much more effective in the decrease in MMP-1 than natural progesterone and testosterone. This greater inhibition by MPA is due to its multiple hormone profiles including progesterone, glucocorticoid, and androgenic activity. Glucocorticoid also has an inhibitory effect on MMP-1 production in some cell types (Jonat et al. 1990, Yang-Yen et al. 1990). However, the MPA-induced decrease in MMP-1 in HESCs was mainly due to its androgenic activity, because FLU recovered the repressive effect of MPA to a level similar to that induced by testosterone or natural progesterone. The repressive effects of progestins on the production of MMP-1 in the human endometrium have been reported before (Marbaix et al. 1992, Lockwood et al. 1998). They showed inhibition of MMP-1 expression using explants of human endometrium (Marbaix et al. 1992) and cultured HESCs (Lockwood et al. 1998); however, the mechanism of the regulation on transcription of MMP-1 by progesterone is not yet understood. Progesterone may regulate MMP-1 gene via non-classical DNA sequences (Hulboy et al. 1997). Furthermore, the ligand-activated progesterone receptor may decrease the amounts of transcription factors by a direct protein-protein interaction, resulting in a decreased binding of the transcription factors on the AP-1 site of MMP-1 promoter (Dong et al. 2002).

In conclusion, the present study demonstrated that the secretion and production of MMP-1 in HESCs in vitro are inhibited by testosterone through androgen receptors. Appropriate regulation of MMP-1 is crucial for uterine remodeling because MMP-1 plays an important role in endometrial tissue degradation that initiates menstruation. These findings indicate that androgen plays an important role in cyclic degradation and renewal of human endometrium.

\section{Acknowledgements}

This study was supported by Science Grants to $T$ Kubota (14571544) from the Ministry of Education, Culture, Sports, Science, and Technology of Japan.

\section{References}

Ajossa S, Guerriero S, Paoletti AM, Orru M \& Melis GB 2002 The antiandrogenic effect of flutamide improves uterine perfusion in women with polycystic ovary syndrome. Fertility and Sterility 77 1136-1140. 
Aplin JD, Charlton AK \& Ayad S 1988 An immunohistochemical study of human endometrial extracellular matrix during the menstrual cycle and first trimester of pregnancy. Cell and Tissue Research 253 231-240.

Apparao KB, Lovely LP, Gui Y, Lininger RA \& Lessey BA 2002 Elevated endometrial androgen receptor expression in women with polycystic ovarian syndrome. Biology of Reproduction 66 297-304.

Bussen S, Sutterlin M \& Steck T 1999 Endocrine abnormalities during the follicular phase in women with recurrent spontaneous abortion. Human Reproduction 14 18-20.

Cermik D, Selam B \& Taylor HS 2003 Regulation of HOXA-10 expression by testosterone in vitro and in the endometrium of patients with polycystic ovary syndrome. Journal of Clinical Endocrinology and Metabolism 88 238-243.

Chandrasekhar Y, Armstrong DT \& Kennedy TG 1990 Implantation delay and anti-deciduogenic activity in the rat by the anti-androgen, hydroxyflutamide. Biology of Reproduction 42 120-125.

Checa MA, Requena A, Salvador C, Tur R, Callejo J, Espinos JJ, Fabregues F \& Herrero J 2005 Insulin-sensitizing agents: use in pregnancy and as therapy in polycystic ovary syndrome. Human Reproduction Update 11 375-390.

Curry TE Jr \& Osteen KG 2003 The matrix metalloproteinase system: changes, regulation, and impact throughout the ovarian and uterine reproductive cycle. Endocrine Reviews 24 428-465.

Dong JC, Dong H, Campana A \& Bischof P 2002 Matrix metalloproteinases and their specific tissue inhibitors in menstruation. Reproduction 123 621-631.

Hampton AL \& Salamonsen LA 1994 Expression of messenger ribonucleic acid encoding matrix metalloproteinases and their tissue inhibitors is related to menstruation. Journal of Endocrinology 141 R1-R3.

Hulboy DL, Rudolph LA \& Matrisian LM 1997 Matrix metalloproteinases as mediators of reproductive function. Molecular Human Reproduction 3 27-45.

Jonat C, Rahmsdorf HJ, Park KK, Cato AC, Gebel S, Ponta H \& Herrlich P 1990 Antitumor promotion and antiinflammation: downmodulation of AP-1 (Fos/Jun) activity by glucocorticoid hormone. Cell 62 1189-1204.

Lockwood CJ, Krikun G, Hausknecht VA, Papp C \& Schatz F 1998 Matrix metalloproteinase and matrix metalloproteinase inhibitor expression in endometrial stromal cells during progestin-initiated decidualization and menstruation-related progestin withdrawal. Endocrinology 139 4607-4613.

Lovely LP, Appa Rao KB, Gui Y \& Lessey BA 2000 Characterization of androgen receptors in a well-differentiated endometrial adenocarcinoma cell line (Ishikawa). Journal of Steroid Biochemistry and Molecular Biology 74 235-241.

Marbaix E, Donnez J, Courtoy PJ \& Eeckhout Y 1992 Progesterone regulates the activity of collagenase and related gelatinases $A$ and $B$ in human endometrial explants. PNAS 89 11789-11793.

Marbaix E, Kokorine I, Henriet P, Donnez J, Courtoy PJ \& Eeckhout Y 1995 The expression of interstitial collagenase in human endometrium is controlled by progesterone and by oestradiol and is related to menstruation. Biochemical Journal 305 1027-1030.

Marbaix E, Kokorine I, Donnez J, Eeckhout Y \& Courtoy PJ 1996 Regulation and restricted expression of interstitial collagenase suggest a pivotal role in the initiation of menstruation. Human Reproduction 11 134-143.

Mertens HJ, Heineman MJ, Theunissen PH, de Jong FH \& Evers JL 2001 Androgen, estrogen and progesterone receptor expression in the human uterus during the menstrual cycle. European Journal of Obstetrics, Gynecology, and Reproductive Biology 98 58-65.

Nagase H \& Woessner JF Jr 1999 Matrix metalloproteinases. Journal of Biological Chemistry 274 21491-21494.
Nagle RB, Knox JD, Wolf C, Bowden GT \& Cress AE 1994 Adhesion molecules, extracellular matrix, and proteases in prostate carcinoma. Journal of Cellular Biochemistry 19 232-237.

Narukawa S, Kanzaki H, Inoue T, Imai K, Higuchi T, Hatayama H, Kariya M \& Mori T 1994 Androgens induce prolactin production by human endometrial stromal cells in vitro. Journal of Clinical Endocrinology and Metabolism 78 165-168.

Noyes RW, Hertig AT \& Rock J 1950 Dating the endometrial biopsy. Fertility and Sterility $13-25$.

Okon MA, Laird SM, Tuckerman EM \& Li TC 1998 Serum androgen levels in women who have recurrent miscarriages and their correlation with markers of endometrial function. Fertility and Sterility $69682-690$.

Rai R, Backos M, Rushworth F \& Regan L 2000 Polycystic ovaries and recurrent miscarriage - a reappraisal. Human Reproduction $\mathbf{1 5}$ 612-615.

Roy AK, Tyagi RK, Song CS, Lavrovsky Y, Ahn SC, Oh TS \& Chatterjee B 2001 Androgen receptor: structural domains and functional dynamics after ligand-receptor interaction. Annals of the New York Academy of Sciences 949 44-57.

Schneikert J, Peterziel H, Defossez PA, Klocker H, Launoit Y \& Cato AC 1996 Androgen receptor-Ets protein is a novel mechanism for steroid hormone-mediated down-modulation of matrix metalloproteinase expression. Journal of Biological Chemistry 271 23907-23913.

Slayden OD, Nayak NR, Burton KA, Chwalisz K, Cameron ST, Critchley HO, Baird DT \& Breener RM 2001 Progesterone antagonists increase androgen receptor expression in the rhesus macaque and human endometrium. Journal of Clinical Endocrinology and Metabolism 86 2668-2679.

Sternlicht MD \& Werb Z 2001 How matrix metalloproteinases regulate cell behavior. Annual Review of Cell and Developmental Biology 17 463-516.

The Rotterdam ESHRE/ASRM-Sponsored PCOS consensus workshop group 2004 Revised 2003 consensus on diagnostic criteria and longterm health risks related to polycystic ovary syndrome (PCOS). Human Reproduction 19 41-47.

Tuckerman EM, Okon MA, Li T \& Laird SM 2000 Do androgens have a direct effect on endometrial function? An in vitro study. Fertility and Sterility 74 771-779.

Tulppala M, Stenman UH, Cacciatore B \& Ylikorkala O 1993 Polycystic ovaries and levels of gonadotrophins and androgens in recurrent miscarriage: prospective study in 50 women. British Journal of Obstetrics and Gynaecology 100 348-352.

Van der Spuy ZM \& Dyer SJ 2004 The pathogenesis of infertility and early pregnancy loss in polycystic ovary syndrome. Best Practice \& Research. Clinical Obstetrics \& Gynaecology 18 755-771.

Woessner JF Jr 1991 Matrix metalloproteinases and their inhibitors in connective tissue remodeling. FASEB Journal 5 2145-2154.

Xu P, Wang YL, Zhu SJ, Luo SY, Piao YS \& Zhuang LZ 2000 Expression of matrix metalloproteinase-2, -9 , and -14 , tissue inhibitors of metalloproteinase-1, and matrix proteins in human placenta during the first trimester. Biology of Reproduction 62 988-994.

Yang-Yen HF, Chambard JC, Sun YL, Smeal T, Schmidt TJ, Drouin J \& Karin M 1990 Transcriptional interference between c-Jun and the glucocorticoid receptor: mutual inhibition of DNA binding due to direct protein-protein interaction. Cell 62 1205-1215.

Received 26 January 2006

First decision 27 February 2006

Revised manuscript received 25 August 2006

Accepted 2 November 2006 